\title{
Penetrating Neck Trauma: Challenges to Anaesthesiologist
}

\author{
Pratibha Jain Shah and Mukunda T* \\ Department of Anaesthesiology \& Critical Care, Pt JNM Medical College, India
}

Submission: May 12, 2019; Published: June 11, 2019

*Corresponding author: Mukunda T, Department of Anaesthesiology \& Critical Care, Pt JNM Medical College, Raipur, India

\begin{abstract}
Background and Aim: Penetrating neck trauma are not only uncommon but can lead to life threatening complications due to vulnerability of vital structures in the small, confined, unprotected area in the younger population. These occur from an accident, homicide or suicide. So, this study was conducted to analyse the clinical profile, type \& level of injury, airway management, choice of anaesthesia technique in such injuries.

Material and methods: This retrospective study included 19 cases of penetrating neck injury who were brought to emergency department and had received treatment. The demographic data, site, type, level \& depth of injury, type of anesthesia, central venous cannulation, airway management, induction agent used, and any complications were recorded and analyzed.

Results: Age range varied from 15 years to 50 years. There were $14(73.68 \%)$ males \& 5(26.32\%) female patients. Majority of penetrating neck injuries were homicidal 11(57.89\%) followed by accidental $4(21.05 \%)$ and suicidal $4(21.05 \%) .15(79.05 \%)$ patients had zone II injuries. In $8(42.1 \%)$ cases of deep penetrating injury of neck, an emergency tracheostomy was done.

Conclusion: We conclude that the majority of penetrating neck injuries was seen in younger age group with male predominance. Early and prompt multidisciplinary management can reduce mortality and morbidity.
\end{abstract}

Keywords: Penetrating neck trauma; Tracheostomy; Anesthetic management

Abbreviations: MILS: Manual in Line Stabilization; PNT: Penetrating neck trauma

\section{Introduction}

Penetrating neck trauma, mostly in the form of assault and self-inflicting stab wounds, is a major contributor to morbidity and mortality in younger population because multiple vital structures are vulnerable to injuries in the small, confined, and unprotected area. It may involve various structures in neck including soft tissues, cartilages, bones, larynx, trachea, oesophagus, pharynx, major blood vessels and important nerves. Penetrating neck trauma may present with an acute or worsening respiratory distress, airway compromise by blood or secretions, surgical emphysema, tracheal deviation secondary to hematoma, acute blood loss when associated with injury to major blood vessels like jugular and carotid, aspiration, hypoxemia and a decreasing level of consciousness [1]. These injuries may be of varying etiology like suicidal, homicidal, accidental, warfare \& of varying patterns like blunt, lacerating, incised and penetrating. Mechanism of injury is very important to understand the extent of damage which in turn helps in better management of shock, hypoxemia or aspiration.

Delay in timely intervention may be fatal in these patients. The management of these injuries requires a multi-disciplinary approach and close collaboration of otolaryngologist, vascular surgeon, anesthesiologist \& psychiatrist [2]. The anesthesiologist not only secures an uncompromised airway but also makes sure that the patient is breathing \& having adequate circulation. The otolaryngologist assesses the injury \& repairs the severed tissues with the aim of restoring swallowing, phonation \& breathing. The psychiatrist plays a vital role in the perioperative period by providing adequate care \& counselling for the patients who are mentally and emotionally disturbed.

\section{Material and Methods}

This retrospective study included 19 cases of penetrating neck trauma admitted from January 2016 to December 2018 at a tertiary care hospital. The data were collected from the records and categorised according to age, sex, type, site and extent of injury, type of anaesthesia, central venous cannulation, airway management, induction agent used, any complications and post op management.

On arrival of the patients in the emergency department, an immediate assessment of the patient was done in the context of injuries (mode, extent, and site) and the overall condition of 
the patient. Wide bore IV cannula was secured; blood sample was drawn for cross matching and routine investigations. Fluid resuscitation with Ringer Lactate was done to maintain adequate circulation. In patients requiring central venous cannulation, the subclavian route was chosen followed by the femoral route. Ranitidine 50mg and metoclopramide $10 \mathrm{mg}$ was given intravenously to all patients as a part of aspiration prophylaxis. In patients with deep penetrating trauma to the neck, urgent stabilisation of the airway was done. Throughout this course, care was given to the positioning of the cervical spine by way of Manual-In-Line Stabilisation (MILS) provided by an assistant.
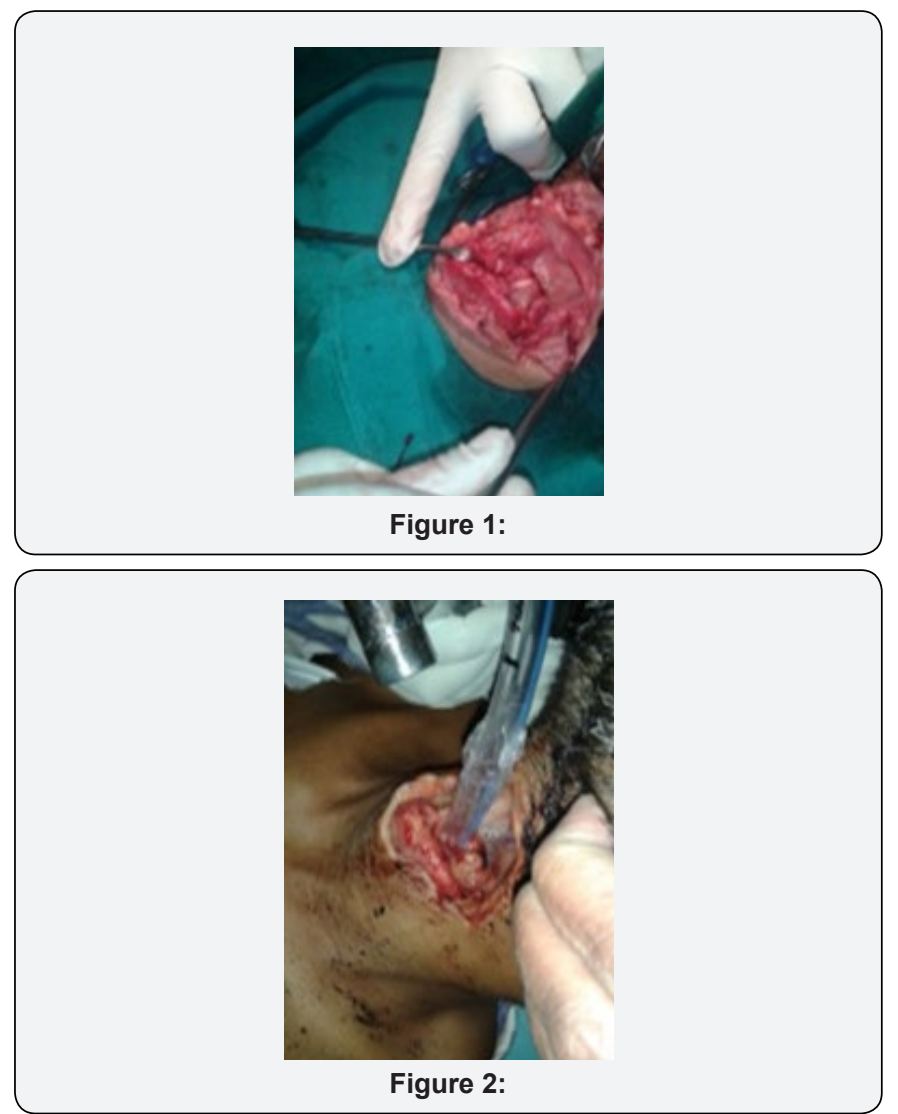

After receiving primary treatment and well informed, high risk written consent, patients were then taken into the operation theatre for tracheostomy and repair of the wound. Monitor (Phillips-MP30) was attached and the baseline heart rate, respiratory rate, B.P. and SpO2 were recorded. Preoxygenation was done through the part of airway communicating with the environment (Figure 1). In hemodynamically stable patients who were taken directly into OT, a smaller sized ET tube was directly pushed through the wound into the trachea after spraying the wound with 4\% Xylocaine (Figure 2). Tracheostomy was done under proper anesthesia, analgesia \& muscle relaxation with iv ketamine as induction agent. After confirmation of the tracheostomy tube in situ, the endotracheal tube was removed subsequently. The nasogastric tube was inserted and fixed before surgical repair of the wound by the surgeon.

Throughout the procedure, NIBP, Sp02, HR, ECG, EtCO2 were maintained within normal limits. Adequate fluids and blood were given.

In the post-operative ward, suction and cleaning of tracheostomy tube was ensured along with the deflation of cuff every 2 hourly. Nasogastric tube feeding was started from 2ndpost-operative day. Orally clear fluids and semisolid food were started on $15^{\text {th }}-18^{\text {th }}$ post-operative day. Gradually partial blocking of tracheostomy tube was initiated, beginning from $10^{\text {th }}-12^{\text {th }}$ post-operative day \& finally removed on $20^{\text {th }}-24^{\text {th }}$ day. Psychiatric evaluation and treatment were started in the post-operative ward simultaneously.

None of the patients had any voice, swallowing or breathing problem after tracheostomy closure. Patients were discharged once oral feeding was established and no evidence of any complication noticed. Hemodynamically stable patients with superficial injury were managed in minor OT under Monitored anesthesia care with adjunct Local anesthetics.

\section{Observation and Results}

Table 1: Demographic Profile \& Zonal Distribution of Neck Injuries.

\begin{tabular}{|c|c|c|}
\hline & Frequency & Percentages (\%) \\
\hline Age & & \\
\hline 15-49 Years & 17 & $89.48 \%$ \\
\hline >50 Years & 2 & $10.52 \%$ \\
\hline Sex & & \\
\hline Male & 14 & $73.68 \%$ \\
\hline Female & 5 & $26.32 \%$ \\
\hline Level of Injury & & \\
\hline Zone I & 4 & $21.05 \%$ \\
\hline Zone II & 15 & $79.05 \%$ \\
\hline Zone III & 0 & 0 \\
\hline
\end{tabular}

The data were analysed by descriptive statistical methods. Out of 19 cases, majority of the patients were male 14 (73.68\%) compared to females 5(26.32\%). Penetrating neck trauma were common in zone II, in which the injuries above the thyroid cartilage were $8(42.1 \%)$ \& between thyroid and cricoid cartilage were $7(36.84 \%)$ and zone I had 4 patients $(21.05 \%)$ (Table 1$)$.

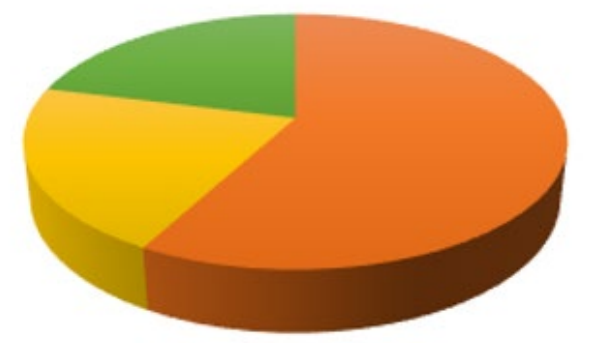

Homicidal $=$ Suicidal $\backsim$ Accidental

Figure 3: Type of Injury. 
Most of the injuries were homicidal 11(57.89\%) followed by suicidal $4(21.05 \%)$ and accidental $4(21.05 \%)$. (Figure 3 ) Five patients required central venous cannulation $(26 \%)$, the subclavian route was chosen in 4 patients (80\%) and femoral route in 1 patient (20\%) (Table 2). Out of 19 cases, general anaesthesia was given to $8(42.1 \%)$ and in $11(57.89 \%)$ cases repair was done under monitored anaesthesia care (Figure 4).

Table 2: Choice of Anaesthesia.

\begin{tabular}{|c|c|c|}
\hline & Frequency & Percentage (\%) \\
\hline General Anaesthesia & 08 & $42.1 \%$ \\
\hline $\begin{array}{c}\text { Monitored Anaesthesia Care \& } \\
\text { Local Anaesthesia }\end{array}$ & 11 & $57.89 \%$ \\
\hline
\end{tabular}

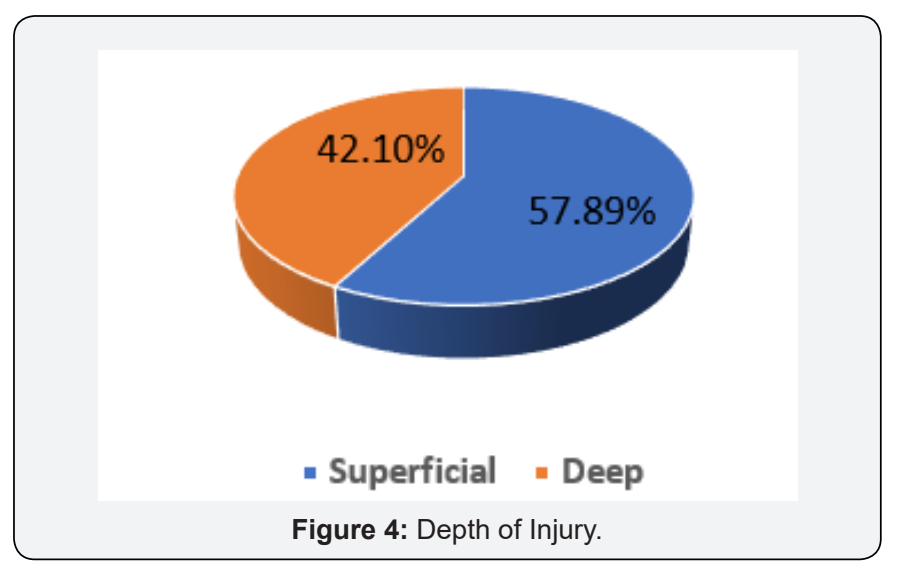

\section{Discussion}

Neck accounts for $3 \%$ of the total body surface area [3]. Fortunately, penetrating airway injuries in neck are rare. Larynx was involved in 5-15\% cases. Anatomically, there are three major zones for surgery in the neck as described by Roon and Christensen [4]: Zone I, thoracic inlet to cricoid; Zone II, cricoid to angle of mandible \& Zone III, above angle of mandible to base of skull. Injuries in Zone II are common. Being a relatively unprotected anatomical region, neck is a common site of potentially dangerous injuries. Penetrating neck trauma (PNT) are defined as injuries that extend deep to or penetrate the platysma. If a neck laceration is limited within the platysma muscle, serious morbidity is unlikely [3].

We observed young \& male predominance in our study. Penetrating neck trauma are most common in males \& younger population as these are actively involved in violent activities and due to their risk-taking behavior [5]. The incidence was higher in low socioeconomic groups due to lack of formal education. A multi-disciplinary approach with the collaboration of the anesthesiologist, otolaryngologist and psychiatrist is needed for the wholesome treatment of the patient. Dealing with the penetrating trauma to the neck requires a different, quicker and improvised approach by the anesthesiologist. These patients should initially be assessed \& managed according to general trauma principles. A primary survey should consist of checking airway, breathing \& circulation. Priority of the anesthesiologist is to secure the airway based on the clinical scenario rather than a preset algorithm considering their own skills and equipment's available. The approach for managing airway by an anesthesiologist can vary from passing ET tube directly through wound, direct laryngoscopy, rapid sequence induction, blind nasal intubation, fibre optic intubation and surgical airway, tracheostomy or cricothyroidotomy.

Priority was given to securing airway \& maintaining hemodynamic as soon as patients arrived in emergency. Airway was secured in 4 patients \& central venous cannulations was done in 5 patients in casualty only. Airway management is a critical factor of prime importance in the management of these patients. Airway stabilisation with adequate pulmonary mechanics is the cornerstone of management in these patients [6]. Preoxygenation should be mandatory in these patients, as most of these cases are warranted difficult airway [7]. Effective preoxygenation of lungs gives an extra time in the management of airway by increasing oxygen content and Functional Residual Capacity which is the principal store of oxygen during apnea.

These patients were full stomach because digestion stops when trauma occurred [7]. As these patients bleed from upper airway, blood is swallowed and accumulated in stomach, therefore risk of regurgitation and aspiration is high. So, aspiration prophylaxis (proton pump inhibitors, prokinetics, antacids, anticholinergics etc) was given to all [8]. Aspiration of gastric contents through insertion of nasogastric tube is difficult in uncooperative patients and relatively contraindicated as it increases chances of injury.

In all patients, iv ketamine was used for induction of anesthesia as other intravenous induction agents have deleterious effects on hemodynamic stability and airway [9]. Manual in Line Stabilization (MILS) should be given by an assistant and practised whenever indicated in order to stabilize the cervical spine as in most of the cases there is injury to the cervical spine [6].

Though CT scan of trachea \& larynx and MRI can be very useful in detecting subtle, previously undetected injuries, but majority of these injuries in emergency do not require identification \& surgical intervention on priority (Gonsalez et al.). Definitive airway management should not be delayed for radiologic studies, since an apparently stable airway can rapidly progress to an upper airway obstruction. Lack of $100 \%$ sensitivity of the diagnostic studies in the detection of injury to vital structures of the neck, a negative exploration, the effort and the additional time rendered for expectant observation led to an increase in the mortality rate associated with cutthroat injuries [10].

In patients with massive bleeding and hemodynamic instability, central venous cannulation was done and managed promptly with iv fluids and blood to maintain adequate circulation [9]. Internal jugular vein is avoided due to the distorted anatomy of the neck. Subclavian route was preferred over femoral route due to ease \& rapidity of insertion, a good hygienic condition and reduced incidence of infection. 
Tracheostomy is a very important practice both from the anaesthetic and the surgical point of view [9]. It is the mandatory requirement to cater for post-operative oedema and possibility of airway compromise. Intraoperatively, passage of a nasogastric tube and fixing it prior to completion of the surgery is advisable for postoperative feeding.

The patients should be monitored with full AAGBI standard monitoring (especially EtCO2) and should be assessed and managed for various complications associated with neck injuries, like respiratory distress due to airway obstruction, hypoxemia, emphysema, acute blood loss, air embolism, aspiration pneumonitis and aphonia.

These patients should be kept NBM post operatively and started on NGT feeding followed by liquid diet and then semisolid food and later solid food to avoid aspiration and facilitate wound healing. Post-operative counselling and psychiatric evaluation is must as most of the cases are self-inflicted and belong to lower socio-economic strait with psychosocial problems. Complications due to surgery are pharyngocutaneous fistula, dysphonia or hoarseness, stenosis of the aero digestive tract and respiratory obstruction.

\section{Conclusion}

We conclude that the majority of penetrating neck trauma was seen in younger male population. Early and prompt multidisciplinary management can reduce mortality and morbidity in penetrating neck trauma.

\section{References}

1. Mercer SJ, Jones CP, Bridge M, Clitheroe E, Morton B, et al. (2016) Systemic review of the anaesthetic management of non- iatrogenic acute adult airway trauma. Br J Anaes 117(S1): i49-i59.

2. Hungund S, Hirolli DA, Shaikh SI (2016) Role of anesthesiologist in managing a rare case of homicidal cut throat injury. Anaes Essays Res 10(1): 114-117.

3. Sharma SB, Amata AO (2016) Penetrating neck injury involving the larynx: A report of three cases. Trauma Emer Care V1(2): 28-32.

4. Rautela N, Verma V, Usmani SA, Mishra A, Singh HP, et al. (2017) Cut throat injuries: the socio-demographic pattern, causes, and outcome at tertiary care hospital of North India. Inter J of Con Med Res 4(1).

5. Jayaram S, Amingad B (2014) A case report: Anaesthetic management of a cut throat injury. J of Evol of Med and Dent Sci 3.

6. Sheffy N, Chemsian RV, Grabinsky A (2014) Anaesthesia considerations in penetrating trauma. $\mathrm{Br} J$ of Anaes 113(2): 276-285.

7. Barak M, Bahouth H, Leiser Y, El Naaj IA (2015) Airway management of the patient with maxillofacial trauma: Review of the literature and suggested clinical approach. Bio Med Res Inter.

8. Robinson M, Davidson A (2014) Aspiration under anaesthesia: risk assessment and decision- making. Cont Edu Anaes Crit Care \& Pain 14(4): 171-175.

9. Bhargava AK, Maj Gandhi BK, Maj Mahajan HK (1998) Anaesthetic management in cut throat injuries 54(1): 53-54.

10. Chappidi AK, Chilukuri A (2018) A study of incidence, cause and management of cut throat injuries. Inter J Oto Head and Neck Surg 4(3): 636-643.

Your next submission with Juniper Publishers will reach you the below assets

- Quality Editorial service

- Swift Peer Review

- Reprints availability

- E-prints Service

- Manuscript Podcast for convenient understanding

- Global attainment for your research

- Manuscript accessibility in different formats

( Pdf, E-pub, Full Text, Audio)

- Unceasing customer service

Track the below URL for one-step submission https://juniperpublishers.com/online-submission.php 